\title{
Restoring Perspective on the IELTS Test
}

\author{
Anthony Green
}

\begin{abstract}
This article presents a response to William Pearson's article, 'Critical Perspectives on the IELTS Test'. It addresses his critique of the role of IELTS as a test for regulating international mobility and access to English medium education and evaluates his more specific prescriptions for the improvements to the quality of the test itself.
\end{abstract}

\section{Introduction}

Pearson seeks to present critical perspectives on IELTS, and to address the test's "wider social, political, and economic implications" (p.\#\#). Claiming to reject the traditional criteria of reliability and validity (although in fact all his criticisms could be framed in these supposedly "de-human" terms), he embraces what he describes as a critical perspective with talk of the "self-sustaining, non-negotiable power" of IELTS. This invokes the critical language testing advocated by Shohamy (2006) and Pennycook's (2001) arguments for a critical applied linguistics which centrally involve, "Turning a skeptical eye towards assumptions, ideas that have become "naturalized", notions that are no longer questioned." (Pennycook 2001, p.7), revealing and contesting the obscured power relationships that shape current practices.

I was therefore rather taken aback to find Pearson cheerfully accepting the assumptions underlying the use of IELTS and its competitors, declaring that, "it is difficult to dispute the need for fair, objective, and internationally-recognised English language credentials to predict an individual's suitability for academia and migration" (p.\#\#). I would suggest that critical approaches have often questioned precisely these assumptions and that consideration of IELTS through a critical lens in the context of the globalized market in English medium tertiary education might help us to better understand the role that IELTS may play in sustaining it.

\section{The function and status of IELTS}

It seems appropriate to start by considering the context in which IELTS operates. IELTS was designed to inform decisions concerning access to English-medium Higher Education Institutions (HEIs) for non-native English speaking (NNES) international students, but not for local students or those from designated native English speaking (NES) countries. 
The global dominance of English and marginalization of other languages in academic exchange, the internationalization of higher education and the burgeoning commercial global market in English medium courses are laden with opportunities for critical engagement.

Alongside similar developments elsewhere, the introduction of full fee costs for international students alongside cuts to state funding by the Thatcher government in the UK and the promotion of education as source of foreign earnings by the Hawke government in Australia in the 1980s ushered in an era in which, increasingly, the 'user pays' for the privilege of attending HEIs in NES countries. The view of higher education as a public good has been displaced by one that regards it as a matter of private advantage (Brown \& Carasso 2013).

Since the introduction of the market reforms of the 1980s, business has boomed. Taking Australia as an example, there were just 13,700 international students in the country in 1983. Today there are around 800,000, including 350,000 at HEIs (internationaleducation.gov.au). Riding the coat tails of this development, annual revenue from English language testing in 2017 for IDP, the Australian partner in IELTS, has now reached 250 million Australian dollars (around US \$185 million) (investors.idp.com). This may seem an impressive sum, but it is a mere drop in the vast ocean of the international education industry and IELTS does not have the power to control the economic tides. Universities Australia (www.universitiesaustralia.edu.au) estimated that earnings from international education reached 31.9 billion Australian dollars (around US \$24 billion) in the financial year to June 2018, making education Australia's third largest export sector (after iron ore and coal) (www.austrade.gov.au). International students are worth 810 million Australian dollars (US \$590 million) annually to Monash University alone (Burton-Bradley 2018).

\section{Test takers and their attitudes}

Pearson rightly argues that we should consider the interests of "the often-ignored, yet key stakeholders in IELTS; the test-takers themselves" ( $p . \# \#)$, but critical theorists remind us that there is another, much larger group whose interests are submerged and that Pearson himself seems to have overlooked. Shohamy (2006), for example, has pointed out that, "In countries where English is not the major national language, it is 
knowledge of the powerful global language, English, that often serves as a class marker enabling entrance to power groups... while excluding others." (p.144). It is typically the children of elite groups - the urban, the wealthy and the highly educated - who have the greatest access to English and the potential to become IELTS test takers. In addition to the access it provides to educational capital, English language proficiency is itself a valued commodity which may enhance the status and employability of students after graduation: an IELTS (or other test) certificate is a sought-after qualification. The promise of enhanced English language abilities is among the factors that make the USA, UK and Australia the most popular destinations for international students.

Test results may thus serve both to reflect and to legitimate processes of selection and exclusion, helping to reproduce and sustain them. However, as Bourdieu \& Passeron (1990) observed, "the inequalities between the classes are incomparably greater when measured by the probabilities of candidature (calculated on the basis of the proportion of children in each social class who reach a given educational level, after equivalent previous achievement) than when measured by the probabilities of passing." (p.153). Learners from disadvantaged social groups tend to be excluded from the educational opportunities that knowledge of English opens up without ever getting far enough in their language learning to aspire to taking a test like IELTS.

In the light of such questions of social justice and access to resources, to what extent should we regard IELTS test takers simply as "victims" rather than beneficiaries of policies that afford many of them privileged access to the rewards of globalisation? Groups that have traditionally performed well on examinations are often among the most vocal opponents of reforms intended to widen opportunity.

Contrary to Pearson's assertion, the IELTS partners have been sponsoring academic research into test taker attitudes for over 20 years, including the long-running IELTS impact study. This research has tended to reveal broadly positive attitudes towards the test, but if test takers do dislike, "the overt design of the test tasks, the taken-for-granted assessment criteria and band score system, and the subtle, normalising function fulfilled by the language featured in the test" (p.\#\#), they generally have the option of choosing a different test.

There are at least three major international competitors for IELTS: TOEFL iBT, the Pearson Test of English: Academic and Cambridge English: Advanced. There are also 
many other smaller, but regionally popular alternatives such as the Canadian Academic English Language (CAEL) test. I wonder whether Pearson believes that the alternatives have better formats, assessment criteria and linguistic representation than IELTS, or that IELTS is, for some reason, the only test in this context that is worthy of his consideration.

\section{International students in HEIs}

The value of international student income to cash-strapped HEIs and the willingness of the students to sign up for their courses have encouraged what has been described as a "deficit" view of international students. This positions the students as "lacking in independent, critical thinking skills; as plagiarisers or rote learners, speaking broken English and having awkward ways of participating in class" (p.6). Responsibility for developing the requisite language skills (as well as covering the examination fees needed to evidence them) is placed firmly on the shoulders of the students themselves. The students are also simply expected to adapt, with or without institutional support, to the academic culture of the receiving HEI.

In contrast, the language and culture of the HEI are regarded as unproblematic and little responsibility is accepted for accommodating to the students' experiences. HEI staff rarely receive training or guidance on managing culturally diverse classes (Harrison 2015). Locally recruited students, (including those characterized as coming from nonEnglish speaking backgrounds) are not typically required to learn how to communicate in cross-cultural settings or take a test in English for academic purposes like IELTS to gain access. The fairness of this selective approach to testing has long been questioned.

Critics such as Jenkins \& Wingate (2015) have argued that policies of this kind, "perpetuate the monolingual culture of UK universities and prevent them from benefiting from the rich linguistic and cultural resources that international students bring with them." (p.48). This is unsatisfactory for international students who are all too often isolated from the local populace, fail to improve their language skills over the course of their university careers and achieve disappointing outcomes relative to their local counterparts. It also represents a lost opportunity for locally recruited students: preparation for participation in world where intercultural interaction is increasingly the norm. 


\section{Flexible standards}

Given the economic value of international student recruitment, it is not surprising that HEIs have been accused of circumventing or ignoring English language requirements when these prove inconvenient (Benzie 2010). Yet it seems perverse to identify IELTS as the primary culprit for this and to depict the HEIs, in a regulatory environment set by immigration and education authorities, as mere "accomplices" in their own admissions policies and practices.

In the UK and Australia, where IELTS is the dominant international test of English for admissions, only a proportion of NNES background students enter HEIs on the basis of an IELTS score. A large-scale study involving 5,675 students at one Australian university found that $11.3 \%$ of the $55 \%$ of NNES background students for whom the university had English proficiency evidence entered via an IELTS score (Oliver, Vanderford and Grote 2012). In another extensive study (cited by Pearson) at a UK university involving 4,342 NNES background students (Thorpe, Snell, Davey-Evans and Talman 2017), the researchers found that just $19.7 \%$ had an IELTS score. Many of the problems identified by both studies occurred when students were accepted via pathways other than IELTS (or its major competitors).

The guidance provided to HEIs by IELTS is explicit on the implications of the band scores: 7.0 is "probably acceptable" and 7.5 more clearly "acceptable" for direct entry to, "linguistically demanding academic courses" such as Medicine or Law. The recommendations are 6.5 and 7.0 for, "linguistically less demanding academic courses" such as Mathematics or Agriculture. When scores are below these thresholds, the recommendation is, "English study needed". In addition, the partners offer an IELTS Scores Guide to help institutions to set locally appropriate performance standards and remind users that, "many diverse variables can affect student performance, of which language ability is but one" (www.ielts.org). In other words, evidence of language abilities should be carefully balanced with other evidence of a student's suitability for a course. This humanistic advice hardly seems to promote, "unquestioned-acceptance of the predictive power of test scores." (p.\#\#), but the power of IELTS to influence behaviour in this context seems decidedly limited. Studies such as Lloyd-Jones, Neame \& Medaney (2011) have revealed that both university staff and students often misinterpret minimum IELTS scores as implying that successful test-takers are ready for university study and should need no further English language support. 
It has rightly been suggested that the IELTS partners could and should do more to support the responsible use of test scores that they recommend. They could be more explicit about the limits on the information provided by IELTS scores and underline that HEIs have responsibility to build the academic literacy of their students. Realizing a positive educational experience is unlikely to be a simple matter of "more English needed". Small, but practical steps that could be taken include the provision of descriptors that more explicitly link IELTS scores to the ways in which students use language at university. Functional descriptions similar to those in the BALEAP Can Do framework for syllabus design and assessment such as "can take part in group work analysing and solving problems" or "can contribute to discussion in seminars" (www.baleap.org) might prove more meaningful to university users than the more linguistically oriented descriptions from the IELTS rating scales such as "uses a range of connectives and discourse markers with some flexibility" or "uses some less common and idiomatic vocabulary and shows some awareness of style and collocation, with some inappropriate choices" (www.ielts.org).

\section{IELTS for migration}

Another pertinent criticism of the IELTS partners, although only mentioned in passing by Pearson, concerns their willingness to expand the scope of test use from its original academic and vocational training purposes to encompass employment and migration decisions. In the academic context, both universities and potential students share an interest in developing the English language abilities needed to access academic study and to participate in the global economy and agree on the need for a certain level of English as a condition for entry to academic courses (although they may disagree on what that level should be). However, the use of language tests to support migration policies is more contested. In this context, enabling migrants to participate fully in society becomes entangled with issues of national identity.

Shohamy (2009) outlines two key issues for test use in this context: the extent to which "knowledge of a new language is always essential for all newcomers in order to function 'properly' in the new society they move to" and, "the rights of a state to impose a language on individuals and whether such an imposition does not violate personal rights of freedom of speech and of democratic principles". (p.48). Pearson may find it "difficult to 
dispute", but it is far from universally accepted that the ability to use a language should be the basis for granting rights of entry or citizenship.

Whether or not one considers it appropriate to use language tests to regulate migration, the expanded use of IELTS for "migration or work" as well as "study" (www.ielts.org) strays from its original purpose: "to measure the English language skills of candidates intending to study in academic or training contexts in English-speaking countries" (Ingram, 2004, p. 18) and so inevitably weakens claims for the validity of the test. There has been what O'Sullivan (2011) described as, "a disquieting lack of empirical evidence" (p.75) to support the use of IELTS scores for other than academic purposes: for example, concerning the language required to sustain social participation among migrants.

\section{Suggestions for improving IELTS}

Pearson sometimes seems to view the IELTS partnership as a cartoonishly malevolent organization, dedicated, rather like SPECTRE in the James Bond movies, to holding the world to ransom. Nonetheless he makes a number of specific recommendations for the improvement of the test including modifications to the test design, the reporting of results and additional services that the test providers could offer to "humanize" the test. Among these is a suggestion that a wider range of accents and language varieties should be used in the Listening test. There is certainly a case to be made for this on grounds of validity. HEIs are diverse environments and whether they are studying in a NES or NNES country, students should expect to encounter a wide range of accents on their courses. There is also some evidence that including multiple accents on a test encourages learners to listen to a range of accents when preparing for the test and that this in turn improves their ability to adapt to accents that they have not encountered before (Harding 2011).

A contrary view holds that test takers who happen to be unfamiliar with the accents chosen for a particular test form will be disadvantaged to the extent that their lack of familiarity with those accents affects their comprehension (Field 2008). With exposure, students are generally able to tune in to the accents of their lecturers and fellow students, but could probably not be expected to do this within the time-frame of a listening test. Ockey \& French (2014) summarized the dilemma that this poses for test designers: "while assessing listening comprehension with speakers who have homogeneous accents may underrepresent the listening construct, including speakers with multiple accents may 
result in unfairly disadvantaging some test takers." (p.4). The IELTS practice of using a limited range of L1 accents may be open to question, but is likely to appeal more to test takers than employing an unpredictable diversity of voices.

Pearson singles out the Writing test for criticism on grounds that it is, "only partially representative of the writing undertaken in the academy" (p.\#\#). Surely a degree of selectiveness is inevitable in a relatively brief test? There are certainly discrepancies between the content of all parts of IELTS and the ways in which students use language in HEIs. The Reading test has been criticized for focusing on slow, careful reading rather than the kind of rapid, selective reading that is so important for academic study and for focusing on local details at the expense of testing the overall understanding of larger textual units. The Speaking and Listening tests bridge the Academic and General Training versions of the test and reflect only some of the features of academic speaking and listening (Douglas 1997, Lynch 2011). It will be interesting to see Pearson's suggestions for test tasks that better represent academic language use. I wonder what he believes a fully representative test would look like.

\section{An outrageous price tag?}

Another complaint is that IELTS is expensive (it costs $£ 222$ or around US $\$ 285$ to take the test in the most expensive location on Pearson's list: China). This is certainly not a trivial sum and it may be unfair that it typically falls to the prospective students, migrants or employees to meet it, but where is the evidence that it is inflated? Clearly a test like IELTS requires considerable resources and its competitors do not seem to be able seriously to undercut it.

I would suggest that the cost of the test should also be judged in the context of the other expenses involved in becoming an international student. It costs 348 British pounds (just over US \$440) to apply for a student visa or the UK and 575 Australian dollars (US \$425) for Australia. An undergraduate course in Business and Economics at the University of Melbourne in 2019 will cost over 40,000 Australian dollars annually (around US $\$ 32,000)$. At the London School of Economics, undergraduates will pay just under 20,000 British pounds (around US \$24,000). Add to this the expense of travel and of living in London or Melbourne and the IELTS fees seem relatively trivial, even factoring in the apparently eye-watering $£ 38$ (just under $\$ 50$ ) for access to additional British Council 
preparation material. Although perhaps there are commercial reasons for not sharing such information, I think greater transparency might help to allay concerns about poor value for money. The IELTS partners could explain where the fees are spent: how much is spent on administration, examiners, invigilation, security?

I do not disagree with Pearson's recommendations on the treatment of results, the provision of feedback and seeking to humanize the test taking experience, although he might acknowledge the improvement that IELTS has made over the years in publicizing the rating scales and augmenting the reporting of results. I also feel we should acknowledge the balance that test providers need to strike between the services they provide and the costs that these involve. No doubt offering free access to preparation courses, personalized feedback and unlimited appeals against any disappointing result would all be attractive to test takers, but I suspect that funding these features might add substantially to the costs. On the other hand, I see little excuse for the longstanding failure of the IELTS partners to meet the basic quality standard of double rating of the speaking and writing tests.

\section{One more for the road}

The IELTS retake policy has long been a cause for complaint for test takers. Until 2006, a test taker could not retake the test for a period of three months. This was source of frustration to those who were under pressure to meet university application deadlines, narrowly failed to achieve the band scores they needed and wished to attempt the test again. Pearson chooses to believe that this change in policy was, "driven by economic imperatives" (p.\#\#), but it might equally plausibly be interpreted as an instance of test developers responding positively to test taker demand. Supporting this interpretation, the partners warn would-be test repeaters that, "Your score is unlikely to increase unless you make a significant effort to improve your English" (www.ielts.org) and report research evidence that writing and speaking scores tend to be particularly difficult to improve. As for accepting results from different test occasions, this policy is not mandated by the IELTS partners, but would seem to be a matter for test users to decide. Although the British General Medical Council requires that their minimum IELTS requirements must be met in a single test sitting, the Australian Health Practitioner Regulation Agency will consider results from different papers across two sittings. 
Given that there are over three million test takers, it is undoubtedly "highly unlikely" that an individual test taker would have any input to the test design. On the other hand, I note from the IELTS website that all test material is reviewed by test takers at selected centres as well as by teachers to ensure that topics are accessible. I do not know what other steps the IELTS partners might currently take to canvass and take account of the views of test takers, but I hope that Pearson will find out and perhaps suggest in his response further practical steps that could be taken.

\section{Conclusion}

Pearson is probably right in suggesting that being apparently "secure, self-sustaining, financially-successful" encourages conservatism: why risk changing a best-selling formula? However, the world of higher education is changing rapidly and its landscape is beginning to look very different to the way it was in 1995 when the current IELTS test took shape. The UK higher education sector now provides qualifications to more students overseas through transnational programmes than to international students in the UK. Many universities in NNES countries are now offering English medium courses to attract a greater share of the international education market and new technology offers new avenues for learning and accreditation. If there is to remain a place for them, IELTS and its competitors will also need to change. Like Pearson, I would encourage them to fulfill their mission by doing so in an inclusive manner that takes full account of the needs of language learners. I do not share Pearson's faith that establishing and funding a powerful new global agency is a necessary, proportionate or plausible means of bringing this about.

\section{References}

Benzie, H. J. (2010). Graduating as a 'native speaker': International students and English language proficiency in higher education. Higher Education Research \& Development, 29(4), 447-459.

Bourdieu, P., \& Passeron, J. C. (1990). Reproduction in education, society and culture. Thousand Oaks, CA:Sage.

Brown, R., \& Carasso, H. (2013). Everything for sale? The marketisation of UK higher education. Routledge.

Burton-Bradley, R. (2018) Poor English, few jobs: Are Australian universities using international students as 'cash cows'? ABC News, https://www.abc.net.au/news/201811-25/poor-english-no-jobs-little-support-international-students/10513590 
Douglas, D. (1997). Testing speaking ability in academic contexts: Theoretical considerations. Princeton, NJ: Educational Testing Service.

Field, J. (2008). Listening in the Language Classroom. Cambridge: Cambridge University Press

Harding, L. (2011). Accent and listening assessment: A validation study of the use of speakers with L2 accents on an academic English listening test. Peter Lang.

Harrison, N. (2015). Practice, problems and power in 'internationalisation at home': critical reflections on recent research evidence. Teaching in Higher Education, 20(4), 412-430.

Ingram, D. (2004). Towards more authenticity in language testing. Babel, 39(2), 16-24.

Jenkins, J., \& Wingate, U. (2015). Staff and Students' Perceptions of English Language Policies and Practices in 'International' Universities: A Case Study from the UK. Higher Education Review, 47(2), 47-73.

Lloyd-Jones, G., Neame, C., \& Medaney, S. (2012). A multiple case study of the relationship between the indicators of students' English language competence on entry and students' academic progress at an international postgraduate university. IELTS Research Reports Volume 11, 2012, 2nd edition, 1.

Lynch, T. (2011) Academic listening in the 21 $1^{\text {st }}$ Century: Reviewing a decade of research. Journal of English for Academic Purposes, 10(2), 79-88.

O'Sullivan, B. (2012). Assessment issues in languages for specific purposes. The Modern Language Journal, 96(s1), 71-88.

Ockey, G. J., \& French, R. (2014). From one to multiple accents on a test of L2 listening comprehension. Applied Linguistics, 37(5), 693-715.

Oliver, R., Vanderford, S., \& Grote, E. (2012). Evidence of English language proficiency and academic achievement of non-English-speaking background students. Higher Education Research \& Development, 31(4), 541-555.

Paton, G. (2013). Foreigners charged up to $£ 35,000$ to take degrees in UK. The Daily Telegraph. 8 Aug 2013.

Pennycook, A. (2001). Critical applied linguistics: A critical introduction. Abingdon, Oxon.: Routledge.

Shohamy, E. (2006). Language policy: Hidden agendas and new approaches. New York: Routledge.

Shohamy, E. (2009). Language tests for immigrants: Why language? why tests? Why citizenship? pages 45-59 in Hogan-Brun, Gabrielle, Mar-Molinero Clare and Patrick Stevenson, (eds). Discourses on Language and Integration, Amsterdam: John Benjamins.

Thorpe, A., Snell, M., Davey-Evans, S., \& Talman, R. (2017). Improving the Academic Performance of Non-native English-Speaking Students: the Contribution of Presessional English Language Programmes. Higher Education Quarterly, 71(1), 5-32. 


\section{The author}

Anthony Green is Professor in Language Assessment at the University of Bedfordshire. He has worked as a teacher, trainer, test writer and designer, examiner, researcher and university lecturer, including briefly working on the IELTS programme. He has served as the President of the International Language Testing Association and on the editorial boards of Assessment in Education, Language Testing, Language Assessment Quarterly and Language Testing in Asia. He has published many articles and books including Exploring Language Assessment and Testing (Routledge) and IELTS Washback in Context (Cambridge University Press), a detailed exploration of IELTS preparation practices and test taker attitudes.

\section{Email: tony.green@beds.ac.uk}

